\title{
The use of hydrodynamic modelling and remote sensing to estimate floodplain inundation and flood discharge in a large tropical catchment
}

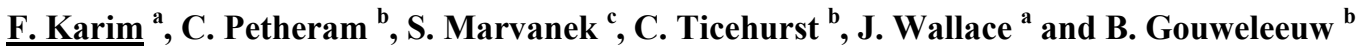 \\ ${ }^{a}$ CSIRO Land and Water, ATSIP Building 145, James Cook University, Townsville, QLD 4811 \\ ${ }^{b}$ CSIRO Land and Water, Christian Laboratory, Canberra, ACT 2601 \\ ${ }^{c}$ CSIRO Land and Water, White Road, Urrbrae, SA 5064 \\ Email:fazlul.karim@,csiro.au
}

\begin{abstract}
This paper describes the application of hydrodynamic modelling in conjunction with remote sensing to estimate flood inundation and discharge in a sparsely monitored and topographically complex tropical catchment in Western Australia. The hydrodynamic modelling was performed using the MIKE 21 model which is a fully dynamic two-dimensional flow model. We used a Shuttle Radar Topographic Mission (SRTM) derived $30 \mathrm{~m}$ digital elevation model (DEM), following drainage enforcement and removal of vegetation to reproduce floodplain topography and stream networks in the model. Laser altimetry derived fine resolution elevation data were used at a number of locations to improve the resolution of key features within the topographic model. Surface roughness parameters were estimated based on a grid based land use map which was developed using a combination of DEM, aerial photos, topographic mapping and Google Earth imagery. The model was calibrated using a combination of gauge water heights and remotely sensed inundation extent maps. The inundation maps were derived using MODIS (Moderate Resolution Image Spectrometer) and AMSR-E (Advanced Microwave Scanning Radiometer for EOS) Satellite image of daily frequency. These water extent maps were combined with SRTM derived $30 \mathrm{~m}$ DEM to obtain estimates of inundation depths across the floodplain. Discharges for flood event in 2002 were computed at several locations on the Fitzroy River using the hydrodynamic model and compared with the gauge records (where available). Results shows gauge records could be over predicted at some locations. However, we are still testing the model for improved calibration and results are inclusive before the completion of final calibration. The method described in this study would help to address the problem of data deficiency in calibrating hydrodynamic models and provides improved estimates of flood discharge. It is intended that this model will be used to investigate the hydrological connectivity of wetlands on the Fitzroy River floodplain and to estimate groundwater recharge to the lower Fitzroy River alluvial aquifers.
\end{abstract}

Keywords: Flood discharge, floodplain inundation, hydrodynamic modelling, MIKE 21 model, remote sensing 


\section{INTRODUCTION}

Although flooding is often perceived as being catastrophic to humans, it has a number of positive implications for riparian, instream and near shore coastal ecosystems. To properly assess in-stream and floodplain ecosystem health and estimate water availability for consumptive use, engineers, scientists, and river management authorities need information on flood magnitude, frequency and duration. Typically stream gauge records are used to quantify flood volume and infer extent of inundation. However, measuring discharge during floods using standard river gauges is problematic. The main reasons for this; (i) water which goes over bank and bypasses the gauge and/or (ii) the use of rating curves that are developed for in-bank flows.

Hydrodynamic models have been in common use for several decades worldwide, for the simulation of flood events for engineering, planning and risk assessment studies (Nicholas, 2003). Based on the modelling objectives and availability of data and resources one can select one-dimensional and two-dimensional or very recently coupled one- and two-dimensional models. Technical considerations include the scale of the model domain, irregularity in land topography, availability of topography data, and complexity of the hydraulic regime. To be useful, hydrodynamic models need to be calibrated. Traditionally flood models are calibrated by comparing in-stream water heights (commonly gauge records) and floodplain inundation (commonly water marks on trees, buildings and electric poles). However, for remotely located catchments, it is often not possible to collect the field data that are necessary to sufficiently calibrate the model. This serves as a major constraint to the use of hydrodynamic modelling in remote and data sparse areas.

In recent years there have been major advances in flood inundation mapping through the use of microwave remote sensing (Alsdorf et al., 2007). However, until relatively recently hydrodynamic modelling and remote sensing for flood mapping have been largely separate disciplines without any clear connection. Interest in integrating these two fields has increased in recent years with the availability of remote sensing data which are freely available near-global and frequent (twice a day).

The main purpose of this study was to assess how well a hydrodynamic model could be used to simulate flood events on a large, remote, data sparse tropical floodplain using the SRTM and other remote sensing imagery.

\section{STUDY AREA AND DATA}

\subsection{Fitzroy river catchment}

The Fitzroy catchment is located in the Kimberly region of northwest Western Australia. It is one of the largest catchments in northern Australia having an area of $94,000 \mathrm{~km}^{2}$ (Figure 1). The Fitzroy River traverses 733 $\mathrm{km}$ from its headwaters in the elevated ranges (altitude $>$ $450 \mathrm{~m}$ ) before meeting the coast in the west. During the wet season (November to April), the Fitzroy can swell to extend $15 \mathrm{~km}$ across the floodplain, with the alluvial sediments covering over $32,000 \mathrm{~km}^{2}$ of the catchment.

The Fitzroy catchment has a semi-arid monsoonal climate with an average rainfall of $560 \mathrm{~mm}$ over the September to August water year, most of which (500 $\mathrm{mm})$ falls in the November to April wet season. Across the region there is a strong north-south gradient in annual rainfall, ranging from $960 \mathrm{~mm}$ in the north to $380 \mathrm{~mm}$ in the south. Flooding in the catchment is not frequent, although one of the largest flood events on record occurred in 2011.

The Fitzroy catchment was selected for this study because the Fitzroy River and its associated

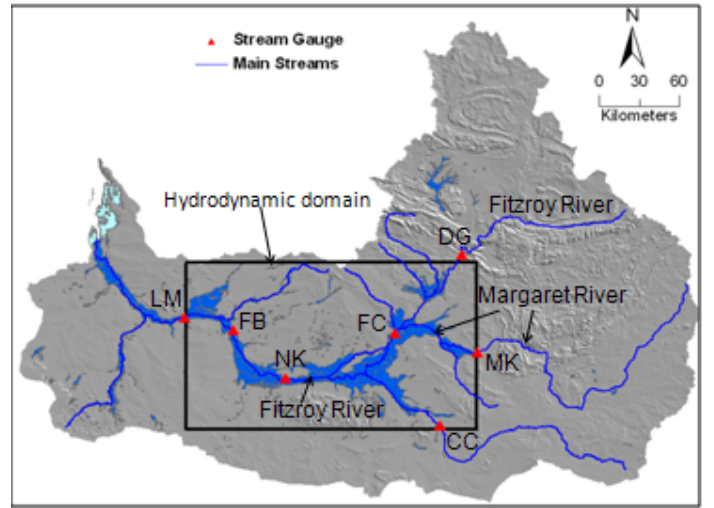

Figure 1. Fitzroy catchment and hydrodynamic model domain showing major rivers and stream gauges (LM: Looma, FB: Fitzroy Barrage, NK: Noonkanbah, FC: Fitzroy Crossing, DG: Dimond Gorge, CC: Christmas Creek, MK: Mt Krauss). Light blue colour represents land subject to inundation.

floodplain are considered to have high ecological value. The link between the river and its floodplain wetlands is highly significant to the maintenance of ecological values. Furthermore the lower floodplain of the Fitzroy catchment contains alluvial aquifers, which are thought to be recharged during flood events. 


\subsection{Data}

In this section we describe the data that were used to build and calibrate the hydrodynamic model. Key data were: i) topography data to construct model grids; ii) grid based land use map to estimate flow resistance; iii) flow data to provide inflow and outflow boundary conditions; and iv) remote sensing data to generate flood maps.

\section{Topography}

We used SRTM derived $30 \mathrm{~m}$ DEM to reproduce the land topography in the model. The DEM was hydrologically corrected by enforcing stream networks and removing vegetation (Gallant and Read, 2009). Laser altimetry (LiDAR) derived fine resolution elevation data were used at a number of locations to improve the resolution of key features within the topographic model. Computational grids in the hydrodynamic model domain were generated by re-sampling the DEM into $90 \mathrm{~m}$ grids to reduce the computational time. In the resampling procedures, an algorithm was used to ensure river topography as seen in the $30 \mathrm{~m}$ DEM was maintained in the re-sampled grids. As the hydrodynamic model boundaries need to remain wet throughout the simulation, the elevations of the boundary grids were lowered by 2 to $3 \mathrm{~m}$.

\section{Roughness}

Manning's roughness coefficient was used to represent hydraulic roughness of land surface to propagate waves. A grid based land use map was developed using a combination of DEM, aerial photos, topographic mapping and Google Earth images with the same size grid as in the hydrodynamic model. These land use grids were converted to roughness grids by an appropriate substitution of land use codes with roughness coefficients. The land uses were classified as major streams (e.g. Fitzroy and Margaret Rivers), small streams (e.g. Christmas Creek), swamp/wetlands, riparian vegetation and savanna. Riparian vegetation and swamp/wetland land use classes were identified based on Geo-Australia 1:250 topographic maps. Stream networks were generated using $30 \mathrm{~m}$ SRTM DEM. The watercourse lines in the topographic mapping 'Hydrography' feature dataset were used to inform the DEM derived stream network so that flow accumulations were forced to follow the river channels as depicted in the topographic mapping. The remainder of the area not covered by the streams, riparian vegetations or swamps was classified as savanna. Initial roughness coefficients were estimated based on published literature (e.g. Arcement and Schneider, 1989; Chow, 1959; Land and Water Australia, 2009) and then refined as a part of the calibration process. Land use is currently being refined using Landsat $(30 \mathrm{~m})$ data.

\section{Stream flow}

Gauged data were used to specify model boundaries and to calibrate the hydrodynamic model. Stream gauging stations are sparse with there being only six gauges in a $730 \mathrm{~km}$ river reach. The time period over which data are available varies between stations. Most gauging stations have less than 10 years data coded as satisfactory or good. We used water level and discharge data for five gauges on the Fitzroy River, of which four are located on the floodplain, one gauge on the Margaret River and one gauge on the Christmas Creek (Figure 1). Discharge data were used at the inflow boundaries (Dimond Gorge, Mt Krauss and Christmas Creek Homestead) and stage heights were used at the sole outflow boundary at Looma. Mean daily discharge and stage height data for these stations were obtained from the Western Australia Department of Water (DoW). Due to the difficulty of gauging flood events on the lower Fitzroy floodplain, the DoW developed rating tables for the floodplain stations using a $1 \mathrm{D}$ hydrodynamic model.

\section{Remote sensing data}

To help calibrate and validate the hydrodynamic model we used several sets of remote sensing data that include MODIS and AMSR-E imagery for the floods in 2001, 2002, and 2007. These data were processed to delineate inundation area and combined with a DEM to generate spatial distribution of inundation depths across the floodplain.

\section{METHOD OF STUDY}

\subsection{Remote sensing}

The method of delineating open waters based on Satellite imageries is briefly described here. It is based on using daily MODIS imagery with the method described in Guerschmann et al. (2010). Since cloud cover often reduces the visibility of the ground, especially during flood events, the MODIS water maps are not always available. To help overcome this problem the MODIS data were complemented with daily passive microwave (AMSR-E), which is much less sensitive to cloud cover, though it has a poor spatial resolution 
( $\sim 10 \mathrm{~km} \times 10 \mathrm{~km}$, compared to $500 \mathrm{~m} \times 500 \mathrm{~m}$ from the MODIS). A sub-grid method described below was developed to distribute the water within each AMSR-E pixel so that it provided data at the same scale as the MODIS data.

\section{Inundation mapping}

Flood maps were produced using the TERRA MOD09GA and AQUA MYD09GA (Daily MODIS imagery) for the flood in 2002 which was one of biggest floods on record. This was done using the Open Water Likelihood (OWL) algorithm as described in Guerschmann et al. (2010). Since cloud cover is often associated with flooding events, it can reduce the amount of cloud-free imagery available for mapping the flood progression. The current method of automatically masking cloud from the imagery uses a cloud band which comes with the imagery. However, it also masked out data affected by minimal atmospheric interference where the ground was clearly visible below. Hence to overcome this, most of the images were manually mapped to remove cloud effects. To help increase the number of daily flood images the AMSR-E passive microwave instrument was used. The AMSR-E can collect data day or night and while it is affected by rain, it is independent of cloud cover. A method described in Ticehurst et al. (2009) was used to produce flood maps resulting in a pixel size of $10 \mathrm{~km} \times 10 \mathrm{~km}$. Due to the large pixel size, a method has been developed to distribute the water within each AMSR-E pixel using information based on historical MODIS flood extent data.

\section{Generation of water depth maps}

Once the flood extent maps are produced, they are combined with the DEM to produce water depth maps. The flood extent maps were geo-referenced to the DEM and a water surface was generated using the method described in Thew et al. (2010). To summarize, it uses the edge of each water body (in the flood extent image) to determine the DEM height of the water's edge. Following this a triangulation method and smoothing algorithm is used to generate the height of the water surface. The water surface height is then subtracted from the DEM to produce water depth for every water pixel in the image. It is then a simple calculation to provide instantaneous water volume for any water body in the image. The progression of the 2002 flood can be seen in Figure 2 as a series of water depth images. It must be noted that any errors in the mapped flood extent, DEM heights, or geometric mismatch between the flood extent maps and the DEM will result in errors propagating through to the water depth images.
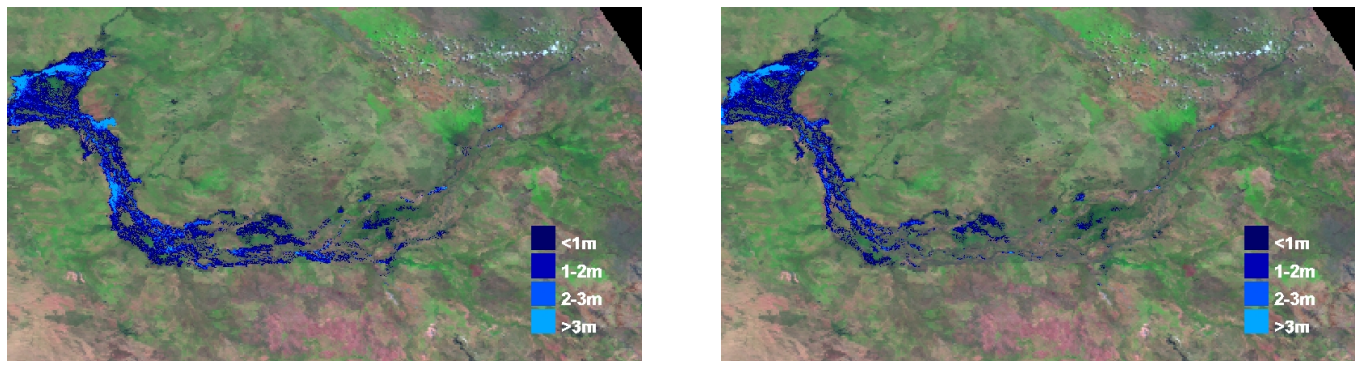

Figure 2. A selection of water depth images generated from MODIS images for the 2002 flood for 27th February and 4th March (left to right).

\subsection{Hydrodynamic modelling}

\section{Model configuration}

The hydrodynamic model was configured for the central floodplain that is thought to significantly contribute to groundwater recharge to the Fitzroy River Valley (FRV) alluvial aquifer. The upstream boundary of the hydrodynamic model was set at Dimond Gorge, well above the floodplain boundary to capture and define the upper catchment flows onto the floodplain and the downstream boundary was set at Looma to avoid any tidal influence on flood discharge, covering an area of $25,000 \mathrm{~km}^{2}$ (Figure 1). The model consists of a water level boundary at Looma and three inflow boundaries at Dimond Gorge, Mt Krauss and Christmas Creek. We used the MIKE 21 hydrodynamic model (DHI, 2009) to simulate flood wave propagation and associated floodplain inundation. The MIKE 21 model is a fully dynamic two-dimensional hydrodynamic model based on the depth-averaged Saint-Venant equations describing the time evolution of water levels and two Cartesian velocity components. Governing flow equations are solved by an implicit finite difference scheme with the variables defined on a space-staggered rectangular grid. The model has been widely used all over the world including Australia for the floodplain hydraulics and flood discharge estimation. The main strength of 
the model is its ability to cope with wetting and drying of floodplain in the time evolution of an overbank flow event and the model can handle a large number of computational grids (in the range of millions). The main limitation is the poor representation of stream channels and therefore the model is not suitable for predicting channelized or very small overbank event.

\section{Simulations}

Water sources on the floodplain include locally generated runoff and stream flows from the upper catchment. Runoff within model domain was simulated using a calibrated rainfall-runoff model. We tested two commonly used conceptual rainfall-runoff models namely Simhyd and Sacramento against gauge records at key locations (e.g. Dimond Gorge, Krauss and Christmas Creek). The hydrodynamic domain was subdivided into 169 sub-catchments and runoff was simulated for each. Simulated runoff were added to the hydrodynamic model as source points at the outlet of each sub-catchment. Sub-catchment boundaries and pour points were generated using $30 \mathrm{~m}$ grid SRTM data from arbitrarily located pour points, typically located at the stream junctions/inflow to main rivers. Water sources from upper catchments were obtained from stream gauge records and added as inflow boundary to hydrodynamic model.

The hydrodynamic model consisted of approx. 3 millions grids $(2308 \times 1344)$ of which approximately $1 / 5$ were dry cells (i.e. not subject to inundation and excluded from computation). Computational time step was derived after satisfying numerical stability criteria for the flood of different magnitudes. A time step of 8 sec was found satisfactory for the 2002 flood, the second largest on record. It took 3 days of computer time to simulate a flood of 12 days. At the boundaries, daily time step water levels and discharges were specified. The model used an inbuilt interpolation technique to derive flow variables at each computational time step. An initial water level map was generated by running the model on dry land for a constant inflow. Initial discharges at all computational grids were specified as zero. To avoid any effects of initial conditions, simulations for the first six hours were not analysed. Model outputs included water surface elevation, depth, velocity and flow flux for each computational grid.

\section{Calibration}

The model was calibrated against a large flood event in 2002. We used a number of MODIS images at different stages of the flood event to compare spatial metrics of inundation area and depth across the floodplain. In addition, gauged water heights at key locations (e.g. Fitzroy Crossing, Noonkanbah and Fitzroy Barrage) were used to compare simulated water levels and time of peak arrival at different locations. During the calibration process, floodplain topography was modified at locations having steep land slopes to ensure model stability. A slight adjustment was also made at the interface between river and floodplain. Grids that represent streams were carefully checked and manually edited to ensure a continuous stream channels. Final calibration was made by changing Manning's roughness coefficient. Surface roughness coefficients were varied iteratively for the major land uses (e.g. savanna, riparian vegetation) within the recommended range to attain a close agreement between observed and simulated water depths. Efforts were made to attain a good match between observed and simulated time of peak arrival at different locations in the floodplain predominantly by controlling roughness coefficients.

Our initial calibration focused on reproducing the inundation area in the model as seen in the MODIS images for the same time period and flowing this, a second calibration attempted to ensure good matching between observed and simulated speed of flood wave. Figure 3 shows a typical comparison between simulated and MODIS detected inundated areas at: a) near the peak and $b$ ) receding conditions. For near peak flooding, the modelled results showed a reasonably good match alongside the Fitzroy River. However, a large number of water

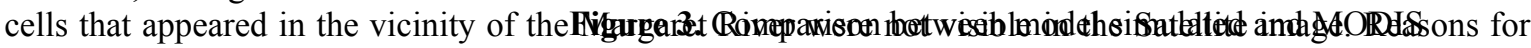
this include the large pixel size of detected inundations (a) 27 Feb 2002 and (b) 8 Mar 2002 
MODIS data or dense vegetation over the water. During the recession of the flood, model predictions are generally higher than the MODIS detected inundations. A limitation of two-dimensional models is that they do not simulate in-bank or small overbank flow event well due to the poor representation of stream channels within the model grid structure. Model calibration is ongoing, however. Simulated mean speed of flood wave propagation was found slightly greater than observed mean speed. This is thought to be primarily due to the use of large computational grids, which reduced the natural meandering of streams and hence travel distance. The large computational grids also produced smoother land topography than reality, which in turn reduced the modeled land surface resistance. To in-part compensate for this issue slightly higher than normal roughness coefficients were used.

\section{RESULTS AND DISCUSSION}

\subsection{Discharge}

Based on these preliminary results we have computed discharges at a few locations on the Fitzroy River. These were compared with DoW gauge data (estimated) at selected locations as shown in Figure 4. The difference between peak discharges is not large except for the Fitzroy Crossing. It can be seen that gauge discharges at Fitzroy Crossing are very large compared with discharges at downstream gauges, this is very unusual for an unregulated river like the Fitzroy. It was noticed that computed discharges were generally small at the beginning of rising stage flood. The reason could be the implementation of 'steady state' initial condition which assumes velocities are zero everywhere. This condition could be improved by using a 'hot start' initial condition which could provide better
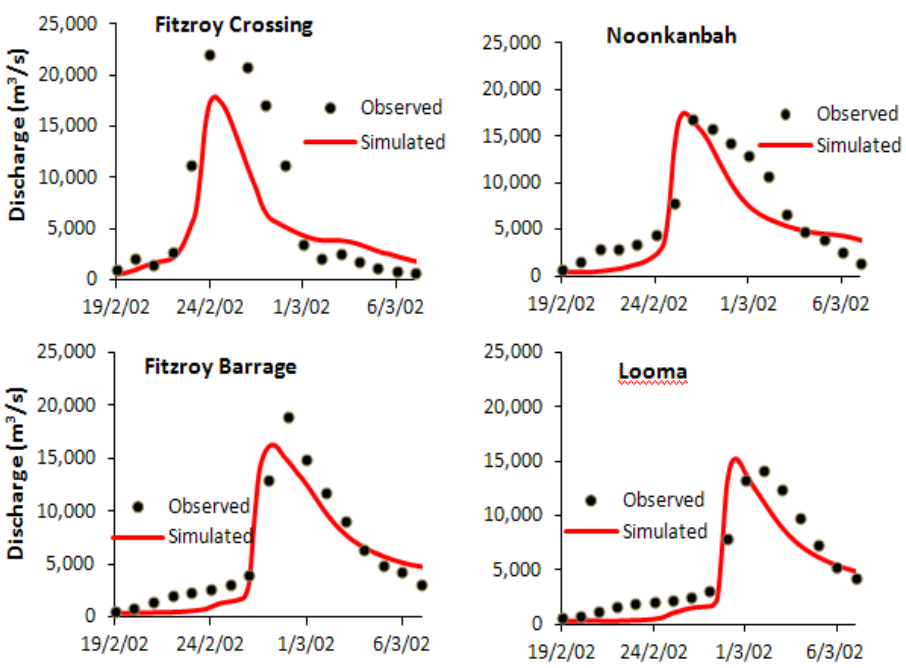

Figure 4. Flood discharges at selected locations on the floodplain estimates of initial discharges.

\subsection{Inundation}

A time history of inundation areas covering the periods of rising, peak and falling stages of the flood in 2002 is shown in Figure 5. MODIS detected total inundation areas for the available days and a comparison with simulated inundation areas are also shown on the same figure. It can be seen that simulated inundations are large compared with MODIS detected inundations and the difference is large at the later stage of the flood. One of the reasons was the poor representation of stream channel that leads to less flow through the channel thus increasing the flows overbank. This problem could be overcome by using a coupled 1-D and 2-D model (e.g. MIKE flood).

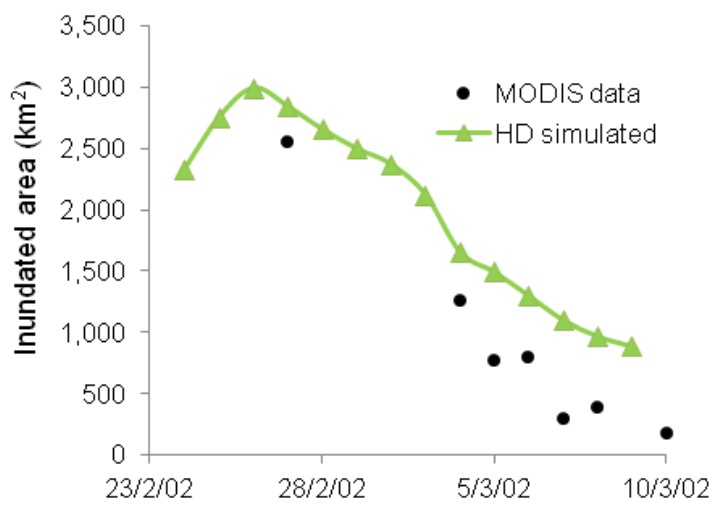

Figure 5. Time varying inundation areas for model domain 


\subsection{Residence time}

Duration of inundation was estimated using time series of spatial water depth grids obtained from MIKE 21 model outputs. An algorithm was developed to distinguish between water and dry grid at 6 hrs time step. By accumulating this information for the period of simulation, a time history of inundation was obtained. Figure 6 shows the spatial distribution of inundation duration for the area covered by hydrodynamic modelling. It can be seen that floodplain areas subject to longer duration of inundation lie to the close proximity of the Fitzroy River. Although large areas in the vicinity of the Margaret River are subject to inundation, the residence time is very small.

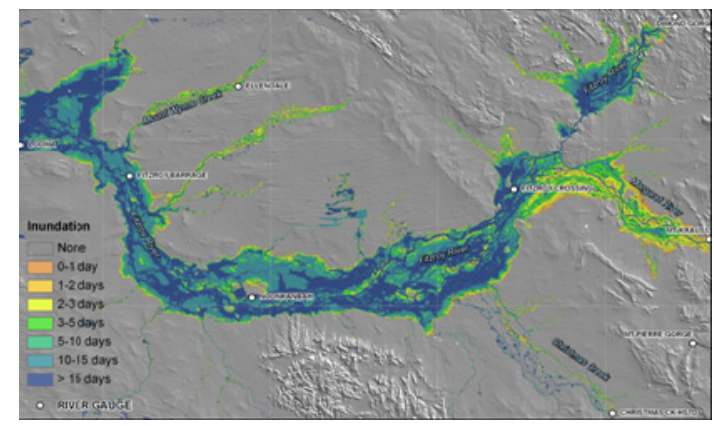

Figure 6. Flood water residence time across the floodplain

\section{CONCLUSIONS}

In this study, a methodology was described to estimate flood inundation and discharge using hydrodynamic modelling in conjunction with remote sensing. The availability of remotely sensed flood inundation maps was found to be very useful for model calibration. Gauge records were found useful to verify model predicted flood speed and in-stream water depths. Preliminary results reveal that the area of inundation is fairly large covering 5 to $10 \mathrm{~km}$ on both sites of the Fitzroy River. A large flooded area occurs either side of the Margaret River. However, only small areas were inundated alongside other creeks. Simulated maximum flood discharges at some locations on the floodplain were found to be less than the DoW gauge records. Results are however, inconclusive before the completion of the final calibration. Potential sources of model error are the use of large grids to reproduce stream channel, implementation of 'steady state' initial condition and usage of simplified land use map to estimate land surface roughness. Once the model has been well calibrated we believe it will be a useful tool for assessing flood discharge and the duration and frequency of wetland connectivity and for broad scale water resource assessments.

\section{ACKNOWLEDGMENTS}

We would like to thank Australian Bureau of Meteorology for supplying rainfall data and Department of Water and Department of Main Roads, Government of Western Australia for river flow data and LiDAR data. We acknowledge DHI, Australia for supplying their hydro-dynamic modelling software and providing technical supports with its application.

\section{REFERENCES}

Alsdorf, D.E., E. Rodríguez, and D.P. Lettenmaier (2007). Measuring surface water from space, Reviews of Geophysics, 45(2).

Arcement, G.J., and V.R. Schneider (1989). Guide for selecting Manning's roughness coefficients for natural channels and floodplain, Water Supply Paper 2339, pp67. US Geological Survey.

Chow, V.T. (1959). Open Channel Hydraulics, pp.679. McGraw-Hill International Edition, Singapore.

DHI (2009). MIKE 21 Flow Model: Scientific Documentation, pp.60. DHI, Denmark.

Gallant, J.C., and A. Read (2009). Enhancing the SRTM data for Australia, In Geomorphometry 2009 (Ed. R. Purves, S. Gruber, R. Straumann \& T. Hengl), 149-154.

Guerschman, J.P., G. Warren, G. Byrne, L. Lymburner, N. Mueller, A. Van-Dijk (2010). MODIS-based standing water detection for flood and large reservoir mapping: algorithm development and applications for the Australian continent. Water for a Healthy Country National Research Flagship Report, Canberra.

Land and Water Australia (2009). An Australian handbook of stream roughness coefficients, pp.28. Land and Water Australia, Canberra.

Nicholas, A.P., and C.A. Mitchell (2003). Numerical simulation of overbank processes in topographically complex floodplain environments, Hydrological Processes, 17(4), 727-746.

Thew, P., C. Ticehurst, J. Lerat, B. Gouweleeuw, J. Gallant, P. Dyce, and G. Walker (2010). CondamineBalonne project final report, pp.70. CSIRO, Canberra.

Ticehurst, C. J, P. Dyce, and J.P. Guerschman (2009). Using passive microwave and optical remote sensing to monitor flood inundation in support of hydrologic modelling, 18th World IMACS/MODSIM Congress, Cairns, Australia, 3747-3753. 